\title{
Parental Perceptions of Their Preschool and Elementary School Children with Respect to Teacher-Family Relations and Teaching Methods During the First COVID-19 Lockdown
}

\author{
Clodie Tal ${ }^{1 *}(\mathrm{D})$, Sigal Tish ${ }^{1}$ (D), Pninat Tal ${ }^{1}$ (D)
}

${ }^{1}$ Levinsky College of Education, Tel Aviv, ISRAEL

*Corresponding Author: clodietal@gmail.com

Citation: Tal, C., Tish, S., \& Tal, P. (2022). Parental Perceptions of Their Preschool and Elementary School Children with Respect to Teacher-Family Relations and Teaching Methods During the First COVID-19 Lockdown. Pedagogical Research, 7(1), em0114. https://doi.org/10.29333/pr/11518

ARTICLE INFO
Received: 25 Oct. 2021
Accepted: 24 Dec. 2021

\begin{abstract}
The goal of this study was to learn about parental perceptions of their preschool and elementary school children with respect to relations with the teachers and various aspects of distance learning used during the first COVID-19 lockdown in Israel. Research was carried out in the summer of 2020 among 602 parents, comprising a representative sample of parents of children in preschool, grades 1-2, and grades 3-6 of the Jewish population of Israel. Participants completed a questionnaire designed for this study that sought to measure attitudes towards aspects of distance learning (e.g., Zoom lessons) and how the teachers related to the children and parents. Findings indicate that the child's age had an impact on how the parent perceives the activities of the children and the teachers with respect to several forms of distance learning imposed by the pandemic. At all ages, parental interpretation of the impact of the pandemic on teacher-family relations was found to contribute to the explained variance regarding parental evaluation of the children's and teachers' activities as well as the variance in attitudes about distance learning (both online and asynchronous). Also, parents of every age cohort reported that they were more involved in their children's distance learning than in encouraging the children to reach out to their friends the parents of third through sixth graders were even less involved than parents of the younger children.
\end{abstract}

Keywords: parents' perceptions, distance learning, preschool children, elementary school children, COVID-19 crisis, family-teachers relationships

\section{INTRODUCTION}

This research examined the perceptions of parents of preschool and elementary school children with respect to relations with the teachers and distance learning methods used during the first COVID-19 lockdown in Israel. "Distance learning refers to education that takes place digitally using shared communication technology and is accompanied by instruction from teachers as well as independent study" (Weissblau, 2020, p. 3). Research was carried out in the summer of 2020, after the first lockdown ended and prior to two later lockdowns and a vaccination drive that led to a significant decline in morbidity as of March 2021 . The coronavirus was first identified in late December 2019 in the city of Wuhan in the Hubei province of China from where it spread rapidly throughout the world, including Israel. On 12 March 2020, COVID-19 was recognized as a pandemic by the World Health Organization (WHO). In China and many countries, including Israel, lockdowns were mandated for the general population and all schools were shut down. The United Nations estimates that 107 countries suspended face-to-face schooling and imposed a lockdown during the early months of the pandemic, meaning that some 862 million schoolchildren worldwide suddenly found themselves engaged in distance learning or with no schooling whatsoever (Viner et al., 2020). Israel moved quickly to distance learning practices in order to ensure the continuity of learning and communication between teachers and students.

Maintaining social distance from individuals who are not immediate family members is believed by health systems throughout the world to be a critical measure for ending the spread of the coronavirus. Such lockdowns, however, together with digital learning and physical distancing from non-family members take an emotional and social toll on children, parents, and teachers. Social distancing runs counter to human nature, as interpersonal interaction is a fundamental need (Baumaister \& Leary, 1995; Ryan \& Decy, 2000, 2017). Although social distancing was intended to prevent the spread of the coronavirus, prolonged social distancing can lead to loneliness and have adverse effects on one's health and emotions (Holt-Lunstad, 2017).

The Israeli Ministry of Education closed all schools on 13 March 2020. Two days later, the Ministry shut down all preschools, daycare centers, and special education facilities. The entire Israeli education system moved to digital media, and distance learning took place for about one month with no orderly guidance from the Ministry of Education - each school developed its own 
curriculum (Dahan et al., 2020). A month or so after the schools had shut down, the Ministry of Education published an outline for distance teaching that resembled the normal daily schedule of preschools and schools (Dahan et al., 2020; Ministry of Education, 2020). Although teachers made use of it and began to prepare weekly curricula for children in the preschools and schools, the outline provoked considerable criticism among parents and teachers, who protested that it did not take into consideration the differences of age or socioeconomic situation of the children in the school system. The Israel Psychological Association published a position paper stating that the program did not accommodate the emotional and cognitive abilities of children of preschool age (Dahan et al., 2020; Israel Psychological Association, 2020). In the wake of this protest, the Education Ministry issued an advisory that the outline was not mandatory, but rather a tool to help teachers organize distance teaching. In parallel, misunderstandings erupted between the Ministry of Education, the Finance Ministry, and the Teachers Union concerning the salaries that teachers were to receive during the period of distance learning (Dahan et al., 2020). The foregoing description may shed some light on the local atmosphere in the Israeli education system before, during, and immediately after the first lockdown as part of the COVID-19 crisis.

International organizations such as UNESCO (2020) and the OECD (Schleicher, 2020) cited parental involvement as a necessary component of distance learning during the COVID-19 crisis, but also as a factor that deepens inequality due to differences in how parents coped with the educational tasks and distance learning of their children (Weissblau, 2020). Thus, it is important to examine how parents of children of various ages perceived their connection with the teachers and with distance learning.

One goal of the study, therefore, was to learn about the perceptions held by the parents of children of various ages (preschool, grades 1-2, and grades 3-6) regarding the child's relations with their teachers and the various components of distance learning during the pandemic. Another goal was to learn which parental variables (e.g., socioeconomic status, fear of infection, concern about the economic situation, number of computers possessed by the family, education, number of children, being an essential worker) are related to these perceptions. Finally, we sought to learn whether and what connection exists between the children's age/grade and their parents' perceptions of relations with the teachers and distance learning.

\section{REVIEW OF THE LITERATURE}

This research proceeds from an argument derived from Bronfenbrenner's ecological systems approach: that distance learning by a child is impossible without parental encouragement and enabling. The ecological systems theory maintains that the child's development is influenced by the interaction between child variables and a matrix of ecological variables (Bronfenbrenner, 1979, 1986). This theoretical approach regards the intense, daily, and direct interactions between the child, the agents of socialization (family members, teachers, and peers), and the physical environment in the microsystem as proximal processes that fuel the engine of development (Bronfenbrenner \& Morris, 2006). Bronfenbrenner and Morris (2006) point out that these direct interactions of children with agents of socialization in the microsystem are influenced by the context (in this research, the context includes the socioeconomic status of the families, the functioning of the educational institutions and its teachers, and constraints imposed by the pandemic). Among the contextual factors that impact the direct connection of the children within the educational framework are parent-teacher relations. Other contextual factors that affect distance learning are equipment and the learning conditions in the children's homes - children at every age level require computers, Internet access at a reasonable speed, and suitable physical conditions (such as a quiet location). These physical requirements in the home are the responsibility of the parents. Preschool children, first and second graders, and special needs children of all ages are in need of mediation and guidance both during the lesson itself and sometimes also in preparation of homework assignments as part of the distance learning. In addition, children of all ages who are at home are in need of ongoing contact with their friends and teachers. Distance learning in a group or class can meet this critical need. And research has found a correspondence between parental involvement and student achievement at every age level (Wilder, 2014).

Parental involvement in their children's education affects the functioning of the schools and preschools because the formal institutions of education share the responsibility for educating children with the parents. This authority is granted to them both by the state and no less by the parents by virtue of their agreement to send their children to the schools. The $21^{\text {st }}$ century has seen considerable attention paid in Israel and elsewhere to the subject of parental involvement, good relations with the educational institution, and how to foster this. In Israel, two committees were established in the 2010s for the purpose of defining and regulating relations between the parents of preschool children and the preschools (Greenbaum \& Fried, 2011) and the parents of secondary school children and secondary schools (Shechtman \& Busharian, 2015). The central argument here, however, is not that parental involvement was suddenly regarded as important in recent years, but that - because of historic and sociological changes (Ichilov, 2010; Tal \& Bar, 2011), and to some extent because of parental demand for a say in their children's education - the establishment sought to define and regulate relations with the parents of schoolchildren in a way that takes into consideration the good of all the students of all ages (Gilat et al., 2017).

"Parental involvement" has been defined in many ways. For this study, we use the definition of Shechtman and Busharian (2015), who define parental involvement as "the totality of activities performed by parents to advance their child, whether at home or in school (or preschool) or any other framework, and the activities performed by teachers to foster good relationships with parents and involve them in their child's education" (p. 16). This broad definition is particularly apt for distance learning during a pandemic lockdown as teachers were in need of parents as mediators to foster connection with the children at home, and the parents themselves were called upon to enable, mediate, encourage, and not interfere with educational efforts made by the teachers. 
Based on a review of published research, Raccah-Addi and Ofir (2013) note that trust among those collaborating in the educational task (in this case the teachers and parents) is particularly important during a period of profound social change. The authors are referring to deep-seated societal transformation that results from a change in the power balance between parents and teachers as parents become more involved in their children's education. In this study, we relate to the lockdown and distance learning imposed upon the teachers, parents, and children as changes that could affect the perception of parent-teacher relations. In fact, children's learning at every age level during this period would be impossible without the involvement of the parents. Indeed, what became evident during this period of massive reliance on digital learning platforms was, on the one hand, the advantages of online learning compared to traditional learning at home, and, on the other hand, large disparities between countries in the very existence of learning programs and sometimes between income brackets within the same country (Dahan, 2020). These disparities can be attributed both to access to computers and good Internet connections and also to the ability and emotional space of parents to assist their children in carrying out the tasks assigned to them (Li \& Lalani, 2020). Li and Lalani (2020) also report differences in the effectiveness of online learning as a function of the student's age and note the importance of adapting the digital environment to younger students to enhance effectivity. In addition to the economic and emotional damage wrought by the social distancing necessitated by the pandemic, the extended duration of distance learning throughout the world (some six to eight weeks in every country during the first lockdown) turned into a large-scale laboratory for examining the advantages and disadvantages of this methodology.

One should keep in mind that the online teaching in schools around the world from late 2019 and early 2020 has taken place in the context of the social isolation of the children and their families, with the teachers themselves experiencing similar social isolation with their own families. In other words, this was not a normal digital learning environment. Previous research has examined the influence of quarantine on the emotional wellbeing and health of those quarantined to prevent the spread of contagious diseases. Brooks et al. (2020) looked closely at 24 studies out of 3,166 that examined the psychological effects of quarantine, particularly with respect to the suspension of classroom teaching. These studies were conducted after quarantines imposed following the outbreak of SARS, Ebola, and widespread cases of the flu in Australia - all instances of shorter quarantines than the current pandemic. From analysis of the 24 studies selected based on the quality of the methodology, they found that quarantine has a dramatic impact on people. It can lead to post-traumatic stress syndrome, confusion, and anger. The research also does not rule out long-term effects of quarantine on the emotional health and functioning of those isolated. Variables that affected the severity of the symptoms were quarantine duration, fear of infection, frustration, boredom, inadequate supplies (of food or other items), inadequate information, financial loss, and stigma.

In their review of studies of parental involvement from an ecological systems perspective of teacher-parent relations (Bronfenbrenner, 1986), Walker and Hoover-Dempsey (2015) emphasize the importance for each side to understand the perspective of the other - that the parents understand the teachers' perspective and vice versa. In this study, we focus on an indepth understanding of how parents perceive relations with the teachers at various age levels of their children.

Several studies performed in different countries (e.g., Bubb \& Jones, 2020, in Norway; Dong, 2020, in China; Lau \& Lee, 2021, in Hong Kong) explored parents' views of distance learning during and after the first lockdown at the beginning of the COVID-19 crisis. Like the present study, these too were based on surveys and investigated either preschool (Dong, 2020) or elementary school (Bubb \& Jones, 2020) children, or both (Lau \& Lee, 2021). However, age was not directly examined as an independent variable that distinguished between preschool, first and second grade children, and third to sixth grade children. The present study explores Israeli parents' perceptions of distance learning and, particularly, their perceptions of the teachers' relations with parents and children. In addition, this study explicitly compares three age groups - preschoolers, first and second graders, and third through sixth graders - as we perceive the transition to school as a period that needs to be explored separately.

\section{Research Goals}

This study seeks to clarify and compare the perceptions of parents of children in early childhood education institutions (preschool and grades 1-2) with the perceptions of parents of children in later grades of elementary school (grades 3-6) with regard to teacher-family relations and aspects of distance learning at each age, during the first six months of the COVID-19 pandemic.

\section{Research Questions}

1. How do the parents of children in preschool, grades 1-2, and grades 3-6 perceive distance learning and the child-teacher relationship following the first six months of lockdown due to the pandemic?

2. Are differences in parental perceptions of distance learning and parent-teacher relations a function of their children's age (preschool, grades 1-2, grades 3-6)?

3. How do parents perceive the effectiveness of the various strategies used for distance learning during the period of the first lockdown?

4. How do parents perceive their own involvement in their children's distance learning and social activities during the first lockdown?

5. What factors influenced parental perceptions about distance learning and relations with the teachers during and immediately after the lockdown? 


\section{METHODOLOGY}

\section{Study Participants}

602 parents participated in this study, comprising a representative sample of parents of children in preschool, grades 1-2, and grades 3-6 of the Jewish population of Israel. Approximately 200 parents were randomly selected from each age cohort of the children by the SekerNet Institute (201 in preschool, 200 in grades 1-2, and 201 in grades 3-6). The sample included 302 mothers and 300 fathers - approximately half mothers and half fathers within each age cohort. Note that some parents had children in more than one age group, but feedback was permissible for only one child per family.

Demographically, some $40 \%$ of the respondents characterized themselves as not religious and $30 \%$ as traditional. The remainder, in relatively equal numbers, reported that they uphold a religious or ultra-Orthodox lifestyle. Professionally, fewer than $10 \%$ were self-employed, while others reported a range of jobs in industry and services. Some $40 \%$ completed college, and another $15-20 \%$ held a graduate degree. Very few (about 1\%) had only an elementary school education. In terms of the number and age of children in the families, there were pronounced differences between parents in the various age cohorts $\left(X^{2}=30.64, p<.001\right)$ : The largest group of parents of preschool children had only two children at home (44\% of parents of preschoolers, compared with $26 \%$ of parents of children in grades $1-2$ and $22 \%$ of parents of children in grades 3-6), while the largest group of parents of elementary schoolers had three children at home. About half the sample was urban while the other half lived in small towns or rural settlements of various sorts. Parents of preschoolers reported far fewer computers at home than parents of older children $\left(X^{2}=33.81, p<.01\right)$ : Only one computer at home was reported by $47 \%$ of preschool parents, $41 \%$ of parents of first and second graders, and $37 \%$ of parents of children in grades $3-6$. In contrast, a computer at home for each individual was reported by $8 \%$ of preschool parents, $14 \%$ of parents of first and second graders, and $26 \%$ of parents of children in grades $3-6$, i.e., the number of home computers increases with the age of the children.

$35 \%$ of the parents of children in elementary school reported five people at home in lockdown, while only four people at home in lockdown were reported by $45 \%$ of preschool parents - the largest category in this age group. In other words, the number of those in lockdown varied with the age group of the children $\left(x^{2}=33.81, p<.001\right)$ : Families of elementary school children had a larger number of family members at home in lockdown. In other aspects of the lockdown, no clear differences were age-related. In the sample at large, at least one parent worked during the lockdown (approximately 50\%) compared with a quarter of the parents who did not work at all during this period.

\section{Research Tools}

Data were gathered from the parents by a questionnaire designed for this study. The questions were prepared in May and June 2020 following discussions with preschool teachers, teachers, and parents, and addressed the perception of activities carried out by the teachers during the distance learning as well as relations between the teachers, students, and parents during the lockdown.

Based on these discussions as well as the research data and theoretical sources cited in the review of the literature, the relevant fields were defined in order to examine parental perceptions of relations with the teachers and of online learning activities. Additional questions were used to understand the possible effects of independent variables on parental perceptions, e.g., demographic variables (e.g., age, education, occupation, number of children in the family, instances of COVID or quarantine in the family) and coronavirus-related variables (e.g., the parent's fear of infection, economic concerns, perception of the child's fear of infection). The draft questionnaire was then submitted to three experts in the field of parental involvement in their children's education, one of whom is also a research methodologist. A pilot study was administered to ten parents and children of various ages to evaluate its suitability for the sample population.

The questions took into consideration the fact that many of the parents who responded have children of various ages. The SekerNet computer system allowed parents to respond to questions about only one child.

The questionnaire was composed of the following sections:

1. Demographic data: parental role (father or mother), age, education, occupation, religiosity, number of children and age of each child (categorized as preschoolers, first and second graders, and third through sixth graders).

2. Family data relevant to the pandemic: is either parent an essential worker; was any family member infected with COVID19; was any family member quarantined.

3. Fear of infection of the respondent, estimated level of their child's fear of infection, assessment of the general level of security.

4. Perceived frequency of the educational activities performed by the teacher (e.g., Zoom lessons, phone calls, home visits, and loaned educational material).

5. Perceived effectiveness of each of the educational activities performed by the teacher.

6. General perception of the care and concern demonstrated by the teacher toward the child; general perception of the teacher's interest in the family's wellbeing; general perception of the effect of the pandemic on parent-teacher relations (stronger, weaker, no change).

7. Parent's self-evaluation of involvement in the learning of each child and encouragement of their child's social contacts.

Upon receipt of the completed questionnaires, Exploratory Factor Analysis (EFA) was used to identify the smallest number of common dimensions. EFA allows for the identification of clusters of questions (dimensions) with common content and their organization into latent factors or indicators through which the research questions were analyzed. In addition, internal 
Table 1. Means, standard deviations, and F-values of the contiguous background variables by age cohort

\begin{tabular}{|c|c|c|c|c|c|c|c|c|}
\hline & $\begin{array}{c}\text { Mean } \\
\text { pre-school }\end{array}$ & S.D. & $\begin{array}{c}\text { Mean } \\
\text { grades 1-2 }\end{array}$ & S.D. & $\begin{array}{c}\text { Mean } \\
\text { grades 3-6 }\end{array}$ & S.D. & $\mathbf{F}$ & $n_{p}{ }^{2}$ \\
\hline Age of parent & $36.10^{\mathrm{a}}$ & 5.67 & $37.91^{\mathrm{b}}$ & 6.06 & $42.33^{\mathrm{c}}$ & 5.97 & $59.15^{\star \star \star}$ & .165 \\
\hline Number of children & $2.71^{\mathrm{a}}$ & 1.19 & $3.20^{\mathrm{b}}$ & 1.49 & $3.09^{b}$ & 1.28 & $7.73^{\star \star \star}$ & .025 \\
\hline Number of family members at home in lockdown & $4.52^{\mathrm{a}}$ & 1.24 & $4.97^{b}$ & 1.58 & $4.78^{\mathrm{ab}}$ & 1.46 & $5.02^{\star \star}$ & .016 \\
\hline Fear of infection during lockdown & 4.04 & 1.66 & 3.92 & 1.64 & 3.91 & 1.69 & 0.43 & .001 \\
\hline Fear of infection after lockdown & 3.82 & 1.57 & 3.88 & 1.51 & 3.90 & 1.57 & .13 & .000 \\
\hline Level of economic security due to the pandemic & 3.71 & 1.49 & 3.75 & 1.45 & 3.83 & 1.49 & .34 & .001 \\
\hline Perceived child's fear of infection & $3.21^{\mathrm{a}}$ & 1.74 & $3.38^{\mathrm{ab}}$ & 1.69 & $3.67^{b}$ & 1.63 & $3.89^{\star}$ & 0.13 \\
\hline
\end{tabular}

${ }^{\star} \mathrm{p}<.05 ;{ }^{\star \star} \mathrm{p}<.01 ;{ }^{\star \star \star} \mathrm{p}<.001$

consistency was measured for each dimension. Alpha Cronbach coefficients for each dimension are presented below in parentheses.

The following dimensions were identified through the factor analysis:

A. Parental perception of the types of children's activities included three dimensions. The common variance explained by the division into these dimensions was $44.4 \%$.

1. Synchronous online learning and computer games: participation in Zoom lessons, other synchronous lesson activities, and computer games carried out alone or with friends (alpha=.71);

2. Asynchronous learning: learning activities beyond participation in the classes (preparation of homework, tasks assigned by the teacher) (alpha=.87);

3. Activities or games outside the formal studies: jigsaw puzzles, Lego, book-reading, brief outings, etc. (alpha=.57).

B. Parental perception of the teacher's activities during distance learning included two dimensions. The common variance explained by these dimensions was $51.1 \%$.

1. Activities by the teacher using Zoom and coordinating the lesson times and topics with the child's parent (alpha=.77);

2. Activities taken by the teacher to be in contact with the child and parents - phone calls, responsiveness to parent's requests, taking an interest in the child's wellbeing (alpha=.79);

C. Parental perception of the value of distance learning included two dimensions. The common variance explained by these dimensions was 36\%.

1. Attitudes about the contribution of distance learning - no contribution; included in this factor are items representing the view that distance learning makes no contribution to the development and learning of the child (alpha=.67);

2. Attitudes about the contribution of distance learning - a positive contribution; included in this factor are items representing the view that distance learning makes a positive contribution to the development and learning of the child (alpha=.71).

\section{Data Analysis}

Data were analyzed using factor analysis to formulate the indicators that represent the dependent variables. Variance analysis was performed to investigate possible differences between age cohorts with respect to the various indicators. In addition, correlations between the indicators (the dependent variables) and the independent variables were calculated. Finally, regression analysis was performed to determine the contribution of the independent variables to explaining the indicators.

\section{The Research Process and Safeguarding the Rights of the Respondents}

Completed questionnaires were submitted anonymously via the Internet in August 2020, and subject to statistical analysis in November-December 2020. The findings were used to elucidate the research questions and were written up in March-April 2021.

\section{FINDINGS}

\section{Life in the Families Six Months After Onset of the Coronavirus}

To better understand the parents' perceptions of the performance of and relationships with the teachers, we examined several aspects of family life during the lockdown and soon after, as we believed that characteristics of the family life could influence the parents' perception of these relations apart from the activities performed by the teacher.

This is divided into two sections: (a) characteristics of family life; and (b) activities that occupied the children at home in the three age cohorts.

\section{Characteristics of family life}

Table 1 presents the means and standard deviations of background characteristics related to life at home during the lockdown: age of the parents, number of children, number of family members together in the lockdown, fear of infection during the lockdown, fear of infection after the lockdown, level of economic security affected by the pandemic, and perceived child's fear of becoming infected. Table 1 also shows comparisons of these variables by age cohort. Also shown is a ranking of the marginal 


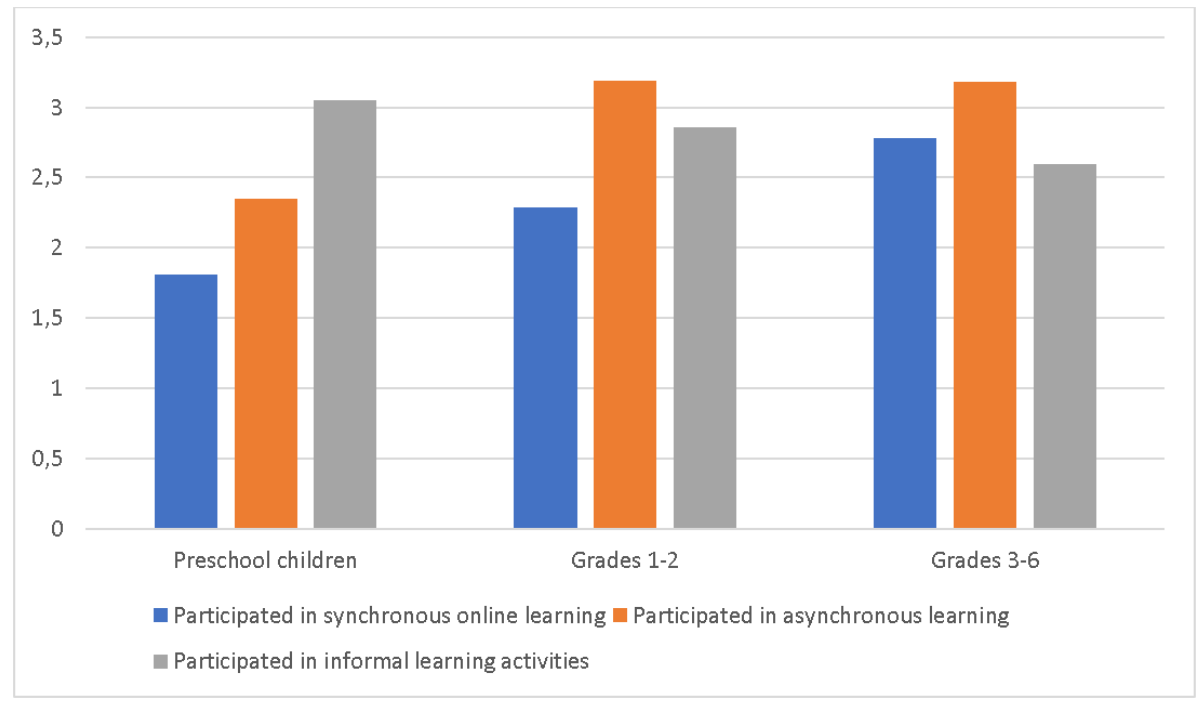

Figure 1. Parents' perception of their children's online learning activities by age cohort

means using superscript letters - "a" indicating the lowest average. These are pairwise comparisons with a Bonferroni correction for multiple comparisons.

Table 1 reveals that the number of children in the family is greater for parents of the older children $(F=7.73, p<.001)$. A greater number of children can also be found, however, among parents of the first and second graders, but this is not significantly different from the parents of the older children ("b"). This has repercussions regarding the number of family members who were together at home during the lockdown, i.e., more family members were at home among parents with a greater number of children ( $F=5.02$, $\mathrm{p}<.005)$.

The perceived fear of one's child becoming infected with the coronavirus is at the medium to medium-high level ( $F=3.89$, $\mathrm{p}<.05)$, and increases with the age of the child: Greater perceived concern can be found for children in grades three through six, while the mean level of perceived concern among first and second graders is no different from what is above and below it ("ab"). The lowest mean level of concern is evident among parents of preschool children. In all age groups, parental fear of becoming infected themselves is higher than the perceived child's fear of becoming infected, which is at a medium-high level. The perceived lower level of fear among the children compared to their own fear of infection is consistent with the widespread belief at the time that the coronavirus infected fewer children aged one to nine than adults.

After a half year of pandemic lockdown, most parents in all three age groups reported that their sense of economic security was not undermined.

\section{Activities of the children at home as a function of age}

Figure 1 presents the means of parents' perception of their children's learning activities during and immediately after the first lockdown. Responses to these questions were given on a scale from 1 (participated in no activities) to 4 (often participated in activities).

Figure 1 reveals differences in parental perception of their children's lockdown activities as a function of age, and these differences are statistically significant. Participation in online synchronous activities (e.g., Zoom lessons, computer games) increases with the child's age $(F=70.08, p<.001)$ - the highest mean participation among children appearing in the highest grades, and the lowest among preschoolers. Similarly, asynchronous learning (e.g., homework and asynchronous assigned tasks) was more intensive among the older children $(F=65.19, p<.001)$ : Though the younger elementary schoolchildren were not significantly different, both groups were more active than the preschoolers. A mirror image emerges for informal learning activities ( $F=29.34$, $\mathrm{p}<.001$ ). Preschool children engaged in more play activities (e.g., Lego, jigsaw puzzles, outings) than the elementary schoolchildren. And among elementary schoolchildren, the younger children were more active than the older ones. Since parent ratings fell within a range of 1 (lower) and 4 (higher), a rating of just above and below 3 can be regarded as a medium frequency of activities. Furthermore, based on parental reports, the children of all ages combined synchronous online learning with asynchronous learning activities, and informal learning through play.

\section{Perception of Teacher Activities During the Lockdown}

Figure 2 presents parental perceptions of online teaching activities and of the teachers' efforts to be in touch with the parents and children.

Figure 2 reveals that parents rated the frequency of the teaching activities as "low", and the frequency of the teachers' communication with the children as "medium-low": All means were in the range of 2.06 to 2.69 based on a scale of four values from 1 (not at all) to 4 (frequent). The parents rated the elementary school teachers higher than the preschool teachers on the frequency of their online teaching activities $(F=22.61, p<.001)$ during the lockdown and shortly afterwards. In addition, the parents rated efforts to be in touch with the parents and children made by the first and second grade teachers as more frequent than the efforts made by the preschool or third through sixth grade teachers $(F=6.96, p<.01)$. Based on parental perceptions, Figure 2 


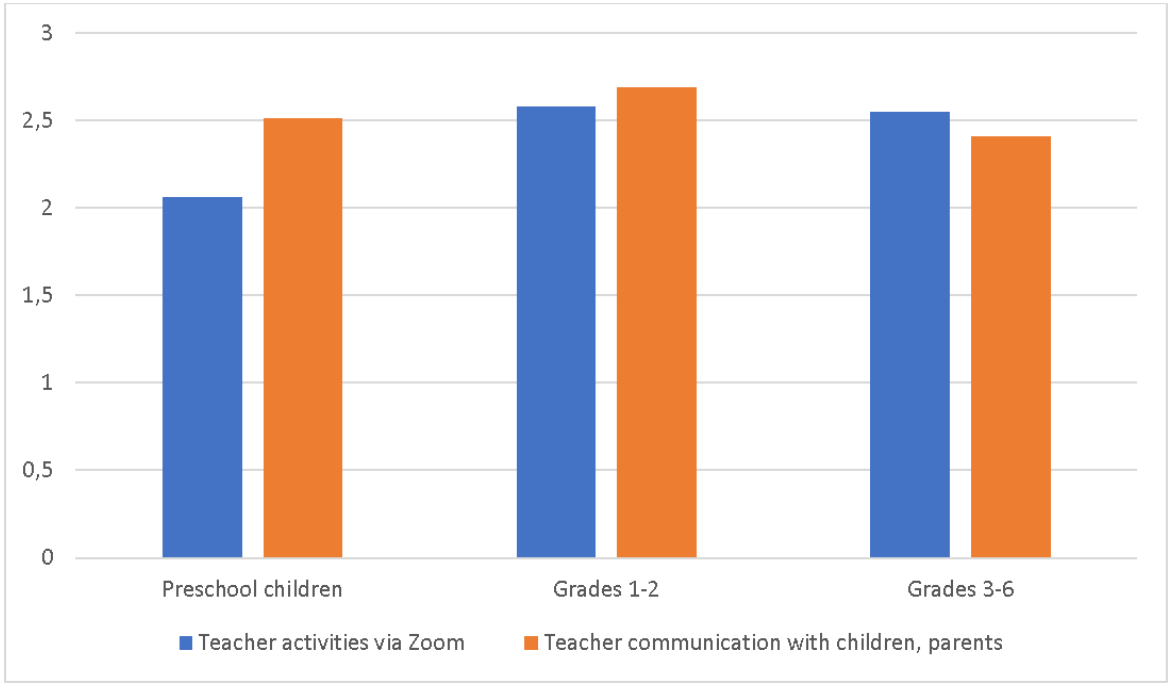

Figure 2. Parents' perception of teachers' activities during the lockdown by age cohort

indicates that the teachers of preschool and lower elementary school grades made more efforts to maintain contact than teach, while teachers of the older children made more efforts to teach than initiate contact with the children or their parents.

An analysis of data that do not appear in Figure 2 reveal that the parents rated the caring and concern of the teachers as somewhat positive (means of 4.21, 4.50, and 4.29 for preschool, grades 1-2, and grades 3-6, respectively). The differences between these groups were borderline significant and did not achieve statistical significance, though the direction was toward a higher rating of showing care and concern about the first and second graders compared with preschoolers and children in grades 3-6. This is consistent with the finding that parents of first and second graders perceive more intensive efforts by the teachers to be in touch with their children than teachers of preschool or third through sixth grades (Figure 2).

The study also included a question related to the impact of the pandemic on relations with the teachers of their children: Parents were asked to indicate whether the pandemic strengthened, weakened, or did not affect the teacher's relations with the parent and the family. $52 \%$ of the parents said the pandemic did not affect relations with the teachers, but some one-third (32\%) at every age group reported that the pandemic did undermine the parent-teacher relationship.

Finally, we examined how parents perceived the contribution of distance learning via a series of questions that were collectively formulated as the indicator "contribution of distance learning". These questions were framed as dichotomies: $1=$ distance learning makes a positive contribution; $0=$ distance learning makes no contribution. It was found that parents of elementary school children rate the contribution of distance learning as more positive than the parents of preschool children $(F=10.92, p<.001)$, with no difference between the two groups of elementary school children $(M=.43$, contributes positively to the learning of first and second graders, $M=.40$ contributes positively to the learning of third through sixth graders, and $M=0.29$ contributes positively to the learning of preschoolers). It is important to note that the contribution of distance learning was rated medium-low by the parents of elementary school children and low by the parents of preschoolers.

\section{Parents' Perception of Their Involvement in Learning and Encouraging Social Contacts}

Parents were asked to rate their own level of involvement in the distance learning of their children and their encouragement of social contacts between their child and the child's friends during the first lockdown and immediately afterwards.

Figure 3 presents the mean parental rating of their involvement with distance learning and of their efforts to encourage their child's social contacts during the first lockdown and immediately after.

Figure 3 reveals that the parents report having been more involved in their child's distance learning than in encouraging his/her social relations. Moreover, there were significant age differences regarding involvement in distance learning ( $F=5.29$, $\mathrm{p}<.01)$ : Parents of third through sixth graders report less involvement in their child's distance learning $(M=4.04)$ while parents of first and second graders report more involvement in their distance learning ( $M=4.49)$, and parents of preschoolers report slightly less involvement $(M=4.39)$. Note that the differences in involvement in distance learning between the parents of children in first and second grade and the parents of preschoolers is not statistically significant. With regard to encouraging their children to stay in touch with their friends, reported efforts were slightly higher than medium, with no significant differences by age.

\section{What factors influenced parental perceptions about distance learning and relations with teachers during and immediately after the lockdown?}

To understand the impact of the background of the parents and children upon participation in the online activities, the parents' perception of the teacher's distance learning activities, and relations with the teacher, a regression analysis was carried out. Table 2 presents the linear regressions for all the research variables. The results deepen our understanding of the impact of the possible variables, to which we added those independent variables that were likely to explain the dependent variables. Table 2 presents the standardized regression coefficient. Beyond the proportion of explained variance of the regression model $\left(R^{2}\right)$, also calculated was the relative portion of each independent variable in explaining the variance based on the standardized coefficients, 


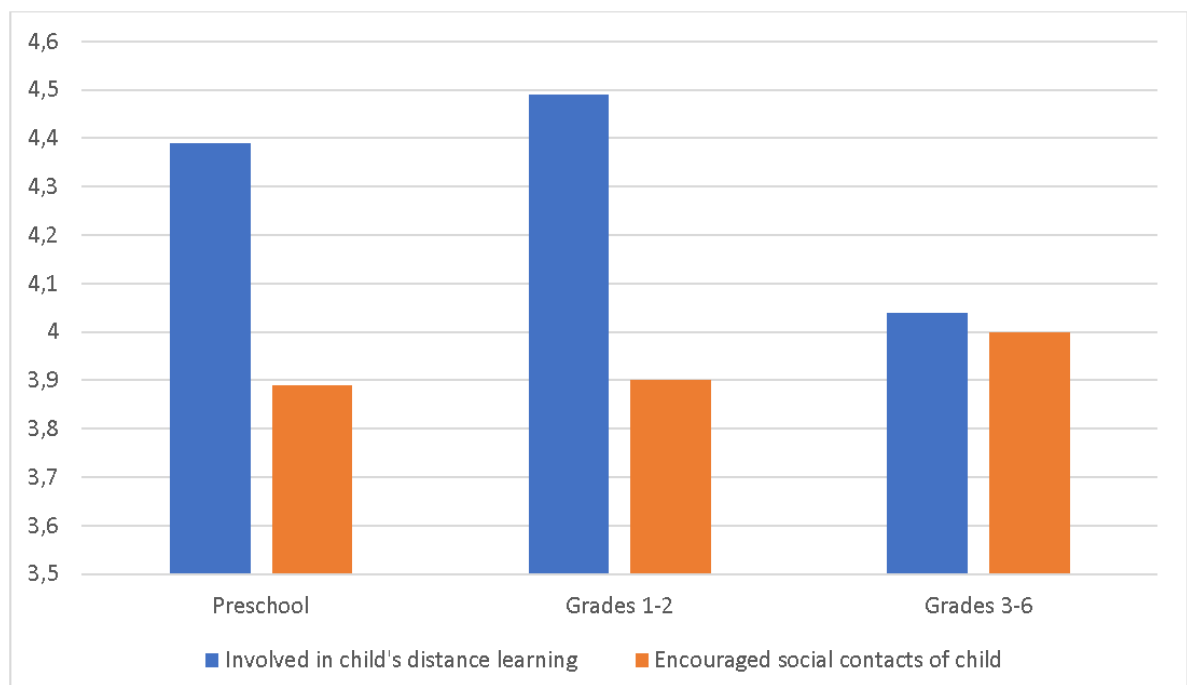

Figure 3. Parents' involvement in distance learning and encouragement of child's social contacts by age cohort

Table 2. Standardized regression coefficients to explain the variance of selected variables

\begin{tabular}{|c|c|c|c|c|c|c|c|}
\hline & $\begin{array}{l}\text { Participation in } \\
\text { synchronous } \\
\text { online learning } \\
\text { and computer } \\
\text { games }\end{array}$ & $\begin{array}{c}\text { Participation in } \\
\text { asynchronous } \\
\text { learning } \\
\text { activities }\end{array}$ & $\begin{array}{l}\text { Participation in } \\
\text { informal } \\
\text { learning } \\
\text { activities }\end{array}$ & $\begin{array}{c}\text { Teachers' } \\
\text { activities- } \\
\text { coordination } \\
\text { and teaching via } \\
\text { Zoom } \\
\end{array}$ & $\begin{array}{c}\text { Teachers' } \\
\text { activities-being } \\
\text { in contact with } \\
\text { child or the } \\
\text { parents }\end{array}$ & $\begin{array}{l}\text { Perception of } \\
\text { distance } \\
\text { learning-no } \\
\text { positive } \\
\text { contribution } \\
\end{array}$ & $\begin{array}{c}\text { Perception of } \\
\text { distance } \\
\text { learning-makes } \\
\text { positive } \\
\text { contribution }\end{array}$ \\
\hline $\begin{array}{l}\text { Preschool vs. } \\
\text { grades 3-6 }\end{array}$ & $-.45^{\star \star \star}$ & $-.43^{\star \star \star}$ & $.29^{\star \star \star}$ & $-.20^{\star \star \star}$ & .03 & $-.09 \sim$ & $-.12^{\star}$ \\
\hline $\begin{array}{c}\text { Grades } 1-2 \text { vs. } \\
\text { grades 3-6 }\end{array}$ & $-.19^{\star \star \star}$ & .01 & $.15^{\star \star}$ & $.08 \sim$ & $.15^{\star \star}$ & -.05 & $.08 \sim$ \\
\hline Age of parent & .02 & .04 & -.07 & $.09 \sim$ & -.06 & -.003 & .02 \\
\hline Religiosity & $-.24^{\star \star \star}$ & $.12^{\star}$ & $.11^{*}$ & $-.12^{\star}$ & $.17^{\star \star}$ & -.08 & $.12^{\star}$ \\
\hline Education & -.02 & .01 & .07 & .01 & -.01 & .02 & .04 \\
\hline $\begin{array}{l}\text { Degree of impact } \\
\text { on teacher's } \\
\text { relations with } \\
\text { family }\end{array}$ & .05 & $.16^{\star \star \star}$ & $.12^{\star \star}$ & $.24^{\star \star \star}$ & $.34^{\star \star \star}$ & $-.23^{\star \star \star}$ & $.25^{\star \star \star}$ \\
\hline $\begin{array}{c}\text { Degree of } \\
\text { financial security } \\
\text { in light of } \\
\text { pandemic }\end{array}$ & .02 & .03 & -.01 & $.07 \sim$ & -.01 & .07 & -.04 \\
\hline $\begin{array}{c}\text { Computers in } \\
\text { household }\end{array}$ & $.13^{\star \star}$ & -.04 & $-.08 \sim$ & .06 & .01 & -.02 & $.13^{\star \star}$ \\
\hline $\begin{array}{c}\text { Number of } \\
\text { family members } \\
\text { together in } \\
\text { lockdown }\end{array}$ & -.02 & -.05 & -.03 & -.03 & .05 & -.06 & -.02 \\
\hline $\begin{array}{c}\text { Anyone in } \\
\text { nuclear family } \\
\text { have COVID-19 }\end{array}$ & -.001 & -.05 & -.02 & $-.08^{\star}$ & -.04 & -.003 & .004 \\
\hline $\begin{array}{l}\text { Did parents work } \\
\text { during lockdown }\end{array}$ & -.03 & -.06 & -.01 & -.03 & -.01 & $-.07 \sim$ & .02 \\
\hline $\begin{array}{c}\text { Anyone in } \\
\text { nuclear family in } \\
\text { quarantine }\end{array}$ & -.04 & .01 & -.01 & .01 & .06 & .05 & $-.08^{\star}$ \\
\hline$R$ & $.55^{\star \star \star}$ & $.49^{\star \star \star}$ & $.37^{\star \star \star}$ & $.43^{\star \star \star}$ & $.44^{\star \star \star}$ & $.28^{\star \star \star}$ & $.37^{\star \star \star}$ \\
\hline$R^{2}$ & $.30^{\star \star \star}$ & $.24^{\star \star \star}$ & $.14^{\star \star \star}$ & $.19^{\star \star \star}$ & $.20^{\star \star \star}$ & $.08^{\star \star \star}$ & $.13^{\star \star \star}$ \\
\hline$F(13,585)$ & $19.61^{\star \star \star}$ & $14.01^{\star \star \star}$ & $7.29^{\star \star \star}$ & $10.44^{\star \star \star}$ & $11.05^{\star \star \star}$ & $3.96^{\star \star \star}$ & $6.94^{\star \star \star}$ \\
\hline
\end{tabular}

${ }^{\star} \mathrm{p}<.05,{ }^{\star \star} \mathrm{p}<.01,{ }^{\star \star \star} \mathrm{p}<.001$

i.e., the relative portion that a specific variable contributes to the total explanation, with the total explanation in percentage expressed by $R^{2}$, such that the total explanation of the variables together equals the value of $R^{2}$.

Table 2 indicates that the age of the child significantly impacts virtually all the research variables. Preschool children, in comparison with children in grades 3-6, participate in fewer learning activities, both online and asynchronously (online learning: $\beta=-.45, p<.001$; asynchronous learning: $\beta=-.43, p<.001$; also, with respect to the frequency of online teaching activities, such as Zoom lessons: $\beta=-.20, p<.001)$, but they do participate in more informal learning activities $(\beta=-.45, p<.001)$. When compared with 
the parents of children in grades 3-6, the parents of preschool children are less likely to assess online learning as making a contribution to the child $(\beta=-.12, p<.05)$. Age explains approximately $10 \%$ of the activity variables, but less with regard to attitudes. However, when comparing parents of children in grades 1-2 with parents of children in grades 3-6, these significant differences diminish. The younger children participate in fewer online activities, according to their parents $(\beta=-.19, p<.001)$, but take part in more informal play activities $(\beta=.15, p<.01)$. The parents of children in grades 1 and 2 also reported more contact between the teachers and themselves and their children $(\beta=.15, p<.01)$. This group has a smaller effect, though, and explains $5 \%$ of the variance or less.

How the parents perceived the effect of the coronavirus on teacher-child relations is positively related to their evaluation of the level of activity of their children and of the teachers themselves in all matters of learning, both online and informally (online: $\beta=.16$, $p<.001$; informally: $\beta=.12, p<.01)$. It also relates positively to their perception that online learning makes a positive contribution to the child's development $(\beta=.25, p<.001)$ and correlates negatively with holding online learning in low regard $(\beta=-.23, p<.001)$. These variables also account for approximately $5 \%$ or less of the explained variance.

It was also found that children of families who identify as religiously observant participate less in online activities, i.e., Zoom lessons or computer games $(\beta=-.24, p<.001)$, but more in informal games $(\beta=.12, p<.05)$ and asynchronous learning activities $(\beta=.11, p<.05)$. More religious than non-religious parents rated positively the teacher's efforts to be in touch with the family $(\beta=.17$, $\mathrm{p}<.01)$ and, in parallel they are more likely to affirm that online learning makes a positive contribution $(\beta=.12, p<.05)$.

The greater fear of becoming infected with the coronavirus correlates directly and positively with online learning activities $(\beta=.09, p<.05)$. This explains no more than $5 \%$ and generally less than $2 \%$ of the variable. The number of home computers is indicative of more intensive computer activity $(\beta=.13, p<.01)$ and also a more positive rating of the contribution of online learning $(\beta=.13, p<.01)$; this variable explains $3 \%$ or $2 \%$ of the variance, respectively.

The fact that someone in the immediate family was in quarantine or sick with COVID-19 shows a very limited connection with online activities: Having a family member sick with COVID suggests fewer online learning activities $(\beta=-.08, p<.05)$ and having someone quarantined relates to a lower evaluation of the contribution made by online learning $(\beta=-.08, p<.05)$. These variables explain about $1 \%$ of the total explained variance.

\section{Summary of Findings}

Three age cohorts of children were studied in this research: preschoolers (aged 3-6), first and second graders, and third through sixth graders.

As expected, the age of the child was related to how the parent perceives the child's and the teacher's activities with respect to several forms of distance learning imposed by the pandemic. The findings indicate that the correlation of age with parental perceptions and evaluations of the child and the teacher is not linear, and that each of the three age cohorts should be considered separately. The parents report that preschoolers, for example, engage in play activities (puzzles, board games) distinct from formal learning and assignments from the teachers more than elementary school children. Preschool children are less fearful of the coronavirus than older children, according to their parents' reported observations, and their rating of the contribution of distance learning to their children's development was also low.

Parents of first and second graders are more likely to evaluate positively the teachers' relationship with and concern for their children than the parents of third through sixth graders. These parents gave a middle score to the frequency of the actions taken by teachers to remain in touch with the children and the family, and rated distance learning activities at even lower frequency. The parents perceive the intensity of the teaching activities by the teachers as mid-range (higher than the preschool teachers and similar to the teachers of grades 3-6). The contribution made by distance learning to the children's development was rated by the parents of first and second graders as mediocre, which was identical to the parents of third through sixth graders, who also regarded the contribution to the children of distance learning as mediocre.

At all ages, parental interpretation of the impact of the pandemic on teacher-family relations was found to contribute to the explained variance regarding parental evaluation of the children's and teachers' activities as well as the variance in attitudes about distance learning (both online and asynchronous). In this context, it should be noted that although approximately half the parents felt that the pandemic did not affect relations with the teachers, about a third felt that the pandemic had weakened this relationship, and only $16 \%$ believed that the situation helped strengthen the teachers' connection with the children and families. The parents' age and religiosity were also related to the frequency of their children's participation in online learning and how the parents evaluated distance learning. Of interest, parents of every age cohort reported that they were more involved in their children's distance learning than in encouraging the children to reach out to their friends - the parents of third through sixth graders were less involved than parents of the younger children.

\section{DISCUSSION}

This research, conducted about six months after the outbreak of the COVID-19 pandemic and some three months after conclusion of the first lockdown in Israel (summer 2020), sheds light on how the parents of children aged 3 through 12 (preschool through sixth grade) perceived the intensity of their children's activities at home, the frequency of teachers' activities in distance teaching and maintaining contact with the children and parents, and which factors impacted these activities.

All in all, the research indicates that parents viewed the contribution of distance learning to their children as mediocre and in need of improvement. We surmise that this is due to the fact that the Israeli educational system as well as the parents was unprepared to cope with the abrupt transition to distance learning imposed by COVID-19 crisis. This seemed to be the case in most 
countries (see, for example, Lau \& Lee, 2021). Norway was an exception. Bubb and Jones (2020) found parents', children's, and teachers' high satisfaction with distance learning during the first lockdown in a municipality that instituted partial, high-quality digital learning before the COVID-19 crisis.

Also evident in the findings is that activities taken by the teachers to keep in touch with the children and families were regarded as important by the parents and as having an effect on the quality of the distance learning. This is consistent with the findings of Gilat et al. (2021) that parents considered relations with the teachers to be very important to the families during the pandemic. Mantovani et al. (2021) also found after studying the perceptions of parents of children 1-10 years old from the Lombardy region of Italy after the first lockdown that most parents (72\%) of children at all age levels expressed satisfaction with the relationship with the teachers, while the contribution of distance learning was accorded a mixed reaction. A personal connection between teachers and children was perceived to be very important, more than the classroom atmosphere itself, and affects scholastic achievements even during normal times (Rucinski et al., 2018). Note also that about a third of the parents reported that the pandemic had an adverse effect upon teachers' relations with the children and parents.

It thus appears important to ensure good relations between teachers, their students, and parents throughout the year, and to emphasize interpersonal relations in preparing for times of crisis as a necessary, though clearly insufficient, condition for learning. Different types of crises may differentially affect the interpersonal relations between teachers, the children, and parents. Keep in mind that in the COVID-19 pandemic, the teachers themselves were directly affected, both as individuals and as parents of children themselves. Therefore, during a future global crisis such as this pandemic, a support and training system for teachers should be made available that will allow them to engage in quality contacts with their students and the parents.

Another key finding is that the age of the children relates to the parents' perception of distance learning, which is consistent with the findings of $\mathrm{Li}$ and Lalani (2020). In the present study, each age cohort was found to have characteristics of its own. For example, preschool and the first two grades of elementary school require greater parental involvement to ensure the participation of the children in online studies. Preschool children seem to require suggestions of non-digital play activities during crisis periods like this pandemic, while first and second graders seem to require frequent contact with and involvement of the teacher. It should also be kept in mind that this study did not directly investigate the quality of the learning of this or any of the age groups under study.

As expected, and also found by Li and Lalani (2020), access to computers at home contributed to greater participation in distance learning. Indeed, studies published by the Knesset Research and Information Center (Weissblau, 2020), and the Crisis Experts [education team] (Dahan et al., 2020) criticized the Israeli Education Ministry for activating distance learning programs without taking into consideration the age of the students, unequal access to computers, and disparities in parental mediation. The slogan "a computer for every child" seems to be necessary, but certainly not a sufficient condition for learning.

Furthermore, parents who are older or those who identify as religious are less likely to participate in the distance learning of their children, suggesting that they may need support and guidance about helping their children or, alternatively, that these children may need more support than children with younger parents or from non-religious families. It was also found that parents are more likely to place emphasis on being involved with their children's distance learning rather than encouraging social contacts with other children - this was true at all ages, but particularly in grades 3-6. Parents seemed to be responding to counsel from the system: Memoranda from the Director-General of the Education Ministry $(2019,2020)$ prior to and early in the pandemic (Weissblau, 2020) reveal that with respect to online learning, the ministry directed teachers to maintain contact with the children's parents and with the children themselves, but did not directly address the importance of social contacts for children outside the school system. We believe that teaching staff and parents should be advised about the importance of encouraging the children to engage in social contacts with peers, particularly during an emergency situation that dictates social distancing, such as the pandemic. In general, Zoom and similar platforms can be recruited to arrange social contacts between children and their peers, if there is awareness of their importance. Indeed, Pascal and Bertram (2021), who examined the perspectives and expectations of preschool children after the first lockdown in England, Scotland, and New Zealand, found that the children were eager to return to their routine and were keen on companionship with other children and opportunities for extended periods of play, particularly outdoors.

In summary, this research shows the importance attributed by parents to the teacher's personal connection with each child and family during the pandemic, both in and of itself and as a factor that affects the quality of the learning. The research also reveals that the age of the children affects the parents' perception of participation in the various learning channels with their contribution to the children. It reveals the need to adapt distance learning to the age group. One should not make do with asking 'yes' or 'no' about online learning, but delve into the needs of each age group for each crisis situation, and construct a "learning package" of relations, methods, and content suitable for each age. The research also reveals that the preferred or desirable methods of learning depend upon additional characteristics of the family: the strength or nature of their religiosity and the age of the parents. Religious parents and older parents may require more guidance by the teachers to help them facilitate their children's participation in the distance learning. It would be valuable to conduct a qualitative study of the perspectives and opinions of parents to clarify what factors led to a not-negligible number of cases in which the teacher's relations with the children and their families declined. This information could serve to train teaching staff for future crisis situations.

The limitations of this research should be noted. This research examined perceptions of parents, not their actual behavior, with regard to relations with the teachers and distance learning some three months after the first lockdown ended and six months after outbreak of the COVID-19 crisis. It would be useful to repeat this questionnaire a year and a half later to study parental perceptions related to distance learning following two additional lockdowns and a return to learning in schools in spite of the continuous presence of COVID-19 in our lives. Distance learning is still sometimes fully or partly employed in classes in which children are expected to remain isolated due to their contact with other children or staff diagnosed with COVID-19. In addition, 
because this research studied parental perceptions of distance learning and not their actual behavior, it would be valuable to examine what was actually learned in the final analysis by the children of preschool, grades 1-2, and grades 3-6.

Finally, this research examined the perspective of the parents concerning distance learning and relations with the teachers. It is also necessary to examine the perspective of the children themselves and the teachers concerning distance learning and their perception of the relations

Author contributions: All authors have sufficiently contributed to the study, and agreed with the results and conclusions.

Funding: The study was supported by a grant from The Mahut Center for information, research and development focused on communication between families and the Educational system.

Acknowledgements: The authors are grateful to the MAHUT Center for their support in conducting this research.

Declaration of interest: No conflict of interest is declared by authors.

\section{REFERENCES}

Baumeister, R. F., \& Leary, M. R. (1995). The need to belong: Desire for interpersonal attachments as a fundamental human motivation. Psychological Bulletin, 117, 497-529. https://doi.org/10.1037/0033-2909.117.3.497

Bronfenbrenner U., \& Morris P. A. (2006). The bioecological model of human development. In R. M. Lerner, \& W. Damon (Eds.), Theoretical models of human development. Vol. 1 of The handbook of child psychology (pp. 793-828). John Wiley \& Sons. https://doi.org/10.1002/9780470147658.chpsy0114

Bronfenbrenner, U. (1979). The ecology of human development: Experiments by nature and design. Harvard University Press.

Bronfenbrenner, U. (1986). Ecology of the family as a context of human development. Research Perspectives, 22(6), 723-742. https://doi.org/10.1037/0012-1649.22.6.723

Brooks, S. K., Webster, R. K., Smith, L. E., Woodland, L., Wessely, S., Greenberg, N., \& Rubin, G. J. (2020). The psychological impact of quarantine and how to reduce it: Rapid review of the evidence. Lancet Rapid Review, 395(10227), 912-920. https://doi.org/10.1016/S0140-6736(20)30460-8

Bubb, S., \& Jones, M. A. (2020). Learning from the COVID-19 home-schooling experience: Listening to pupils/parents/carers and teachers. Improving Schools, 23(3) 209-222. https://doi.org/10.1177/1365480220958797

Dahan, Y., Abu-Rabia-Queder, S., Yonah, Y., Biton A., Hassan S., Levy G., Massalha, M., Safrai Y., \& Pinson H. (2020). Corona crisis and its effect on the Israeli education system. Crisis-Experts Organization [Hebrew]. https://www.crisis-experts.org.il/wpcontent/uploads/2020/04/pdf

Dong, C., Cao, S., \& Li, H. (2020). Young children's online learning during COVID-19 pandemic: Chinese parents' beliefs and attitudes. Children and Youth Services Review, 118, 1-9. https://doi.org/10.1016/j.childyouth.2020.105440

Gilat, I., Botanero, A., \& Tal, C. (2021). Perspectives of mothers about relations with preschool teachers during the corona period. Researchers@Early Childhood, 13, 31-49 [Hebrew]. https://kindergarten.levinsky.ac.il/wpcontent/uploads/sites/13/2021/02/nekudat_mabat_imahot_kesher_im_ganenet.pdf

Gilat, I., Zimet, G. R., Tal, C., \& Tabak, E. (2017). Parental perception of the status, role, and functioning of the preschool teacher, Researchers@Early Childhood, 5, 90-121 [Hebrew]. https://kindergarten.levinsky.ac.il/wpcontent/uploads/sites/13/2018/01/tfisot_horim_ganenet.pdf

Greenbaum, C. W., \& Fried, D. (Eds.). (2011). Relations between the family and the early childhood education system: Status report and recommendations. Yozma - Center for Knowledge and Research in Education, Israel Academy of Sciences and Humanities [Hebrew]. http://education.academy.ac.il/SystemFiles/23022.pdf

Holt-Lunstad, J. (2017). The potential public health relevance of social isolation and loneliness: Prevalence, epidemiology, and risk factors. Public Policy and Aging Report, 27(4), 127-130. https://doi.org/10.1093/ppar/prx030

Ichilov, O. (2010). The establishment of public education in Israel and the retreat from it. In O. Ichilov (Ed.), Privatization and commercialization of Israel's public education (pp. 21-50). Ramot [Hebrew]. https://doi.org/10.1007/978-1-4020-9570-2_5

Israel Psychological Association. (2020). Position paper: The distance learning plan outlined by the Ministry of Education for preschool children [Hebrew]. https://www.psychology.org.il/sites/psycho/UserContent/files

Lau, E. Y. H., \& Lee, K. (2021). Parents' views on young children's distance learning and screen time during COVID-19 class suspension in Hong Kong. Early Education and Development, 32(6), 863-880. https://doi.org/10.1080/10409289.2020.1843925

Li, C., \& Lalani, F. (2020). The COVID-19 pandemic has changed education forever. This is how. World Economic Forum. https://www.weforum.org/agenda/2020/04/coronavirus-education-global-covid19-online-digital-learning/

Mantovani, S., Bove, C., Ferri, P., Manzoni, P., Cesa Bianchi, A., \& Picca, M. (2021). Children 'under lockdown': Voices, experiences, and resources during and after the COVID-19 emergency. Insights from a survey with children and families in the Lombardy region of Italy. European Early Childhood Education Research Journal, 29(1), 35-50. https://doi.org/10.1080/ 1350293X.2021.1872673

Ministry of Education. (2019). Emergency procedures for the education system, 3 January [Hebrew]. https://apps.education.gov.il/Mankal/horaa.aspx?siduri=218\#_Toc256000249 
Ministry of Education. (2020). Distance learning in preschools [Hebrew]. https://meyda.education.gov.il/files/ mosdot/pre_school_online_learning.pdf

Pascal, C., \& Bertram, T. (2021). What do young children have to say? Recognizing their voices, wisdom, agency, and need for companionship during the COVID pandemic. European Early Childhood Education Research Journal, 29(1), 21-34. https://doi.org/10.1080/1350293X.2021.1872676

Raccah-Addi, A., \& Ofir, E. (2013). Teachers' trust in role partners and innovation in school. Studies in Educational Administration, 33, 163-192 [Hebrew]. https://avneyrosha.org.il/resourcecenter/resoursesdocs/Teachertrustlevels.pdf

Rucinski, C. L., Brown, J. L., \& Downer, J. T. (2018). Teacher-child relationships, classroom climate, and children's social-emotional and academic development. Journal of Educational Psychology, 110(7), 992-1004. https://doi.org/10.1037/edu0000240

Ryan, R. M., \& Deci, E. L. (2000). Self-determination theory and the facilitation of intrinsic motivation, social development, and wellbeing. American Psychologist, 55(1) 68-78. https://doi.org/10.1037/0003-066X.55.1.68

Ryan, R. M., \& Deci, E. L. (2017). Self-determination theory: Basic psychological needs in motivation development and wellness. Guilford Press. https://doi.org/10.1521/978.14625/28806

Schleicher, A. (2020). How can teachers and school systems respond to the COVID-19 pandemic? Some lessons from TALIS, OECD Education and Skills Today. https://oecdedutoday.com/how-teachers-school-systems-respond-coronavirus-talis/

Shechtman, Z., \& Busharian, O. (Eds.). (2015). Parent-teacher interactions in secondary education: Status report and recommendations. Yozma - Center for Knowledge and Research in Education, Israel Academy of Sciences and Humanities [Hebrew]. http://education.academy.ac.il/Admin/Data/Publications/parent-theacher\%20interaction-heb.pdf

Tal, C., \& Bar, T. (2011). Summary: An historical perspective on relations between the family and the school system. In C. Greenbaum \& D. Fried (Eds.), Relations between the family and the early childhood education system: Status report and recommendations. Yozma - Center for Knowledge and Research in Education, Israel Academy of Sciences and Humanities [Hebrew]. http://education.academy.ac.il/SystemFiles/23022.pdf

UNESCO (2020). COVID-19 Educational Disruption and Response, March 29 update. https://en.unesco.org/covid19/educationresponse

Viner, R. M., Russell, S. J., Croker, H., Packer, J., Ward, J., Stansfield, C., Mytton, O., Bonell, C., \& Booy, R. (2020). School closure and management practices during coronavirus outbreaks including COVID-19: A rapid systematic review. The Lancet Child and Education Health, 4(5), 397-404. https://doi.org/10.1016/S2352-4642(20)30095-X

Walker, J. M. T., \& Hoover-Dempsey, K. V. (2015). Parental engagement and classroom management. In E. T. Emmer, \& E. J. Sabornie (Eds.), Handbook of classroom management (2nd ed., pp. 459-478). Routledge.

Weissblau, E. (2020). Emergency distance learning while educational institutions are closed due to the Coronavirus outbreak. Knesset Research and Information Center [Hebrew]. https://fs.knesset.gov.il/globaldocs/MMM/6c81656c-de69-ea11-811300155d0af32a/2_6c81656c-de69-ea11-8113-00155d0af32a_11_13773.pdf

Wilder, S. (2013). Effects of parental involvement on academic achievement: A meta-synthesis. Educational Review, 66(3), 1-21. https://doi.org/10.1080/00131911.2013.780009 